\title{
Permanência e desaparecimento: a cidade e o cinema de Tsai Ming-Liang'
}

Cecilia Antakly Mello²

1. Esse artigo faz parte da pesquisa "Movimento e espaço urbano no cinema contemporâneo", financiada pela FAPESP - Bolsa de Pós-Doutorado (2008-201 I) e realizada junto ao Departamento de Cinema, Rádio e Televisão, ECA-USP. Em 2010 , com apoio da FAPESP, realizei estágio de pós-doutorado como "Visiting Fellow" da Taipei National University of the Arts, Taiman. Agradeço ao Prof. Lee Daw-Ming pela supervisão durante minha estada em Taipei.

2. Jovem Pesquisadora Fapesp, Departamento de História da Arte, Escola de Filosofia, Letras e Ciências Humanas, Unifesp Campus Guarulhos. E-mail: cicamello@yahoo.co.uk 


\section{Resumo}

Pensar no cinema como uma forma de arte afinada com o urbano e capaz de proporcionar uma flânerie imaginária através da cidade me parece ponto de partida para uma análise dos filmes do diretor malaio/taiwanês Tsai Ming-Liang. sua obra ocupa uma posição de centralidade no cinema contemporâneo devido a seu engajamento privilegiado com o espaço urbano e a arquitetura. Para conhecê-la melhor, este artigo traz uma análise juntamente com uma entrevista com o cineasta, que se complementam como reflexão sobre a obra e o espaço que ele ocupa no cinema contemporâneo.

\section{Palavras-chave}

Cinema, China, Tsai Ming-Liang

\section{Abstract}

To think of cinema as a form of art which shares an affinity with the urban and promotes an imaginary flânerie through the city space seems to be an excellent starting point for an analysis of the films of Malay/Taiwanese director Tsai Ming-liang. His work occupies a position of centrality in contemporary world cinema in its privileged engagement of space and architecture, and in its indissociable rapport with the urban space. This article is dedicated to an analysis of three of his films from the point of view of their relationship with the city, and is complemented by an interview with the director. They together offer a reflection on his work and his role in contemporary cinema.

\section{Keywords}

Cinema, China, Tsai Ming-Liang 
A relação entre cinema e cidade tornou-se um ponto central na teoria do ano 2 número 3 audiovisual de meados dos anos 1990 em diante, e como sugere Julia Hallam “é cada vez mais reconhecida como a base arquetípica para a análise da experiência visual e sensorial, forma e estilo, percepção, cognição e o sentido da imagem fílmica e do texto fílmico" (HALLAN, 2010, p. 277). Dentro da multiplicidade de estudos que emergiram nos últimos anos, os escritos de Giuliana Bruno se destacam como especialmente originais e instigantes. Seu trabalho expande a qualidade sensorial da experiência cinematográfica identificada por Gilles Deleuze, que assinalou nos anos 1980 uma mudança do paradigma óptico para o háptico (DELEUZE, 1985). Em seu monumental Atlas of emotion, Bruno sugere ser o cinema uma arte essencialmente espacial:

\footnotetext{
Preso no olhar Lacaniano, cujo impacto espacial não fora explorado, o espectador de cinema se transformou em um voyeur. Por contraste, quando falamos de site-seeing sugerimos que, por conta da mobilização espaçocorporal de um filme, o espectador é na realidade um voyageur, um passageiro que atravessa um terreno háptico, emotivo. (BRUNO, 2007, p. 15-16)
}

Na passagem de ótico para háptico, de voyeur para voyageur, a ideia do cinema como herdeiro direto da perspectiva Renascentista é posta por terra, e a apreciação do espaço fílmico passa a ser considerada a partir da experiência tátil e do movimento. O cinema, de acordo com Bruno, proporciona uma viagem emotiva através de espaços múltiplos. Ao evocar a conhecida frase de Michel de Certeau "toda narrativa é uma narrativa de viagem - uma prática espacial”, Bruno sugere que "o cinema é a narrativa de viagem por excelência. As narrativas fílmicas, geradas por um espaço, e em geral filmadas em locação, nos transportam para um lugar" (BRUNO, 1997, p. 46). Assim, o visionamento de filmes é, nos termos de Bruno, “uma forma imaginária de flânerie" (BRUNO, 2007, p. 16).

Pensar no cinema como uma forma de arte afinada com o urbano e capaz de proporcionar uma flânerie imaginária através da cidade me parece um excelente ponto de partida para uma análise dos filmes do diretor malaio/taiwanês Tsai Ming-liang. Sua obra sem dúvida ocupa uma posição de centralidade no cinema contemporâneo devido a seu engajamento privilegiado com o espaço 
urbano e a arquitetura. Esse espaço urbano, a partir de Os rebeldes do deus néon (Qing Shao Nian Ne Zha) em 1992 até Goodbye, Dragon Inn (Bu San) em 2003, incluindo seus teledramas, é a cidade de Taipei, capital de Taiwan. O espectador fiel desta obra singular que, construída a partir de uma teia de temas, personagens e espaços afins que se alimentam uns dos outros de filme a filme, começará em pouco tempo a criar intimidade com o mundo cinematográfico de Tsai. Minha própria experiência com seu cinema guiou grande parte das investigações sobre a relação entre o cinema e o espaço urbano, já que foi através do visionamento de seus filmes que senti como se tivesse ido repetidas vezes a Taipei, antes mesmo de ter estado lá fisicamente. Através dessa forma imaginária de flânerie, passei a conhecer e reconhecer as avenidas, os mercados noturnos, as ruas cheias de motocicletas, um cinema, a passarela de pedestres, um apartamento, e vários banheiros públicos.

Levando-se em conta a revalorização do cinema como uma arte espacial, e partindo de uma categorização do espaço como algo dinâmico, definido acima de tudo pela mobilidade (MASSEY, 2008), este artigo vai procurar identificar a relação entre espaço, tempo e memória nos filmes A passarela se foi (Tianqiao bu jianle, 2002), Adeus, Dragon Inn (Bu san, 2003), It's a dream (Shi meng, 2007), traçando um paralelo entre a efemeridade da cidade e a efemeridade do cinema, à luz de suas constantes mutações. Como tentarei evidenciar, os três filmes partem de uma observação acerca do desaparecimento urbano, no primeiro de uma passarela de pedestres e nos outros dois de um antigo cinema, mas dão um passo adiante ao aliar essa reflexão a um questionamento correlato acerca da transformação da arte cinematográfica como até então a conhecíamos. Ao fazêlo, evidenciam a tensão inerente ao cinema - a arte realista por excelência de André Bazin - entre a permanência e o desaparecimento, entre o movimento e a stasis, entre a vida e a morte.

\section{A forma da cidade e o coração de um mortal}

Se o espaço é uma categoria dinâmica, e a mobilidade das cidades uma versão exagerada da espacialidade em geral ((LURY e MASSEY, 1999, p. 231), é plausível supor que, em determinados momentos históricos, uma determinada cidade ou 
ano 2 número 3

Temáticas

livres

cidades sofrerão com maior intensidade do que outras com o intrínseco fluxo espacial. Escrevendo na época do Segundo Império francês e confrontado com as mudanças radicais promovidas pelo prefeito de Paris, Georges Haussmann, que por 17 anos foi responsável por um programa de modernização radical da cidade sob encomenda de Napoleão III, o poeta Charles Baudelaire soube melhor do que ninguém trazer a instabilidade do espaço urbano para seus versos em “Tableaux Parisiens”, incluídos na coletânea Les fleurs du mal (As flores do mal), (BAUDELAIRE, 1964). Em "Le cygne" ("O cisne”), por exemplo, ele escreve: “a velha Paris não é mais", e encerra entre parênteses "(a forma de uma cidade muda mais rápido, ai de mim! que o coração de um mortal)" (BAUDELAIRE, 1964, p. 107) ${ }^{3}$. Sabe-se que Baudelaire foi o flâneur urbano por excelência, atravessando a Paris que deixava para trás seu passado medieval e abraçava a modernidade, com bairros antigos dando lugar a novas avenidas. Ele escreveu sobre a forma da cidade e o coração dos mortais, e transformou em versos essa relação complexa, evidenciando de que modo o espaço urbano está impregnado de memória e emoções.

Nas últimas duas décadas, essa noção adquiriu um significado especial no contexto das transformações radicais observadas em várias cidades asiáticas, que parecem estar acontecendo com maior intensidade do que em outras partes do mundo, ou pelo menos com menos respeito ao passado. Também é verdade que o cinema contemporâneo em diferentes cidades vem registrando esse espaço urbano instável. Um dos melhores exemplos desse olhar privilegiado sobre a cidade efêmera são os dois últimos filmes da Trilogia de Fontainhas do diretor português Pedro Costa, No quarto da Vanda (2000) e Juventude em marcha (2006). Na China, a obra de Jia Zhang-ke é talvez a mais instigante entre inúmeras outras dedicadas ao desaparecimento do velho e ao surgimento do novo, com destaque para sua obra-prima Em busca da vida (Sanxia haoren, 2006), filmado em Feng Jie, cidade às margens do rio Yangtze na China e que em 2006 estava prestes a ser completamente submersa pela represa da Usina das Três Gargantas. O cinema, com a sua capacidade única de captação do 
real, parece nos permitir ver, mais do que qualquer outra arte, a natureza dessa instabilidade, refletindo sobre ao invés de simplesmente refletir a cidade, nos termos de Dudley Andrew (2010, p. 39).

Eu diria que o cinema de Tsai, assim como o de Costa e Jia, contém uma preocupação análoga com o espaço urbano efêmero, e que ele articula essas preocupações através de uma estética original nos filmes A passarela se foi, Adeus, Dragon Inn e It's a dream. Como mencionado anteriormente, o espaço urbano no seio das preocupações temáticas e estéticas encontradas em muitos dos filmes de Tsai, incluindo A passarela se foi, Adeus, Dragon Inn, é Taipei e seus arredores. A cidade foi a principal base da ocupação japonesa de Taiwan de 1895 a 1945, antes de se tornar a capital da República da China sob a liderança de Chiang Kai-shek. Com a gradual abertura política nos anos 1970 e o consequente relaxamento da legislação urbanística, que incluiu a rescisão da proibição de construção de novos hotéis e arranha-céus, e principalmente após o fim da lei marcial em 1987, Taipei sofreu uma modernização apressada com planejamento esporádico ou inexistente. Essa modernização foi seguida de um esforço para melhorar a qualidade de vida na cidade densamente povoada, com a construção de uma rede subterrânea de metrô (conhecida em inglês como Municipal Rapid Transit - MRT), grandes avenidas e parques, todos nas últimas duas décadas. Tais transformações tiveram um impacto sobre o cinema de Tsai Ming-liang, como ele explicou em diversas entrevistas, especialmente durante os anos 1990 e início de 2000. Aqui ele fala em 1997 ao Cahiers du Cinéma:

Taipei é uma cidade em constante mudança. E pude observar essas mudanças, de um estágio simples e primitivo para a complexidade caótica de uma metrópole moderna. ... Eu senti uma espécie de impotência diante dessa mudança inexorável. A cada filme, tentei reconhecer as diferentes etapas desse processo. ... Eu sou muito sensível à atmosfera da cidade: somos incessantemente confrontados com as mudanças a nível visual e afetivo. (REYNAUD, 1997, p. 36)

Nesta citação, de ecos baudelairianos, Tsai alude ao efeito das transformações urbanas em seus habitantes e também à forma como o cinema, capaz de 
ano 2 número 3

Temáticas

livres

registrar e preservar um espaço em desaparecimento, se relaciona com estas mudanças. Disso Tsai parece derivar uma urgência, de sobretons nostálgicos, de filmar esse espaço instável, e esta parece constituir uma das principais motivações de seu cinema.

Um desses espaços é a área em torno da Estação Central de Taipei, onde costumava haver uma passarela para pedestres sobre uma grande avenida. A passarela era uma ligação entre lugares além de um lugar de passagem e de comércio. Foi nela que a personagem Shiang-Chyi comprou um relógio de Hsiao Kang antes de partir de viagem a Paris em Que horas são aí? (Ni Nei Bian Ji dian), realizado por Tsai em 2001. Ela agora está de volta a Taipei e descobre que A passarela se foi neste filme de 25 minutos, concebido como uma espécie de “coda" para Que horas são aí. O retorno é nada mais do que desorientador para Shiang-Chyi. O filme abre com cinco planos nos quais ela aparece cercada de superfícies que transmitem ou refletem imagens em movimento. O primeiro é um plano-sequência de dois minutos no qual ela está parada de costas para a câmera olhando para um enorme telão montado na parede de um prédio comercial, o que cria um efeito de mise-en-abîme. O telão transmite propagandas de videogames, cosméticos e restaurantes. Shiang-Chyi permanece imóvel diante das imagens, assim como a câmera, enquanto ao seu redor todos se movem com rapidez. Nos próximos planos as superfícies reflexivas em torno dos edifícios formam uma infinidade de ilusões óticas que contribuem para o efeito desorientador desse espaço na personagem, que parece estar perdida ou buscando algo. É possível também observar a recorrente imagem de uma mulher empurrando uma mala de rodinhas (Lu Yi-Ching), andando rapidamente de um lado para o outro. Após essa abertura, que dura os cinco minutos iniciais do filme e cria um ambiente de difícil compreensão, finalmente vem à tona a razão da perplexidade de ShiangChyi e do ir e vir incessante da mulher com a mala: ambas buscavam uma maneira de atravessar a avenida, diante da ausência da antiga passarela.

Shiang-Chyi decide então seguir Lu Yi-Ching e ambas cruzam a avenida em um local proibido. Uma vez do outro lado, a dupla é parada por um policial de trânsito que lhes dá uma multa, explicando que a passarela fora substituída por uma passagem subterrânea, tornando-se assim invisível. Isso de fato ocorreu na 
Taipei real, conforme o próprio cinema parece tornar evidente (a passarela ainda estava lá em Que horas são aí? filme do ano anterior). Trata-se aqui do que escolhi chamar de um impulso arqueológico do cinema, derivado da qualidade ontológica da imagem fotográfica e de sua capacidade única de preservar o real como um documento. Assim é que, diante de um espaço instável, o cinema é capaz de preservar diferentes camadas da realidade, tomadas em tempos diferentes, e que por sua vez serão percebidas e vivenciadas em outros tempos. Além de atestar para a constante mudança do tecido urbano em Taipei, a confusão de Shiang-Chyi demonstra de que modo as memórias estão contidas em espaços, apesar de serem comumente percebidas como um fenômeno puramente temporal. Ao retornar à sua cidade, ela parece procurar por aquilo que estava escrito/inscrito em sua memória, mas o espaço outrora familiar está marcado por uma falta. Não por acaso, Shiang-Chyi também se dá conta de que perdeu sua carteira de identidade após cruzar a avenida, e busca o policial de trânsito para verificar se ele por ventura havia ficado com o documento por engano. A perda do cartão de identidade acentua sua própria confusão em um espaço estranho, que não se encaixa em sua memória. Aqui, a cidade é tanto familiar quanto assustadora, tanto heimlich (em inglês homely - familiar) quanto unheimlich (unhomely - estranho), nos termos de Freud ([1919] 1976), que soube conceituar a ambivalência dessa classe de "susto" no qual o familiar permanece escondido em algum lugar - até mesmo dentro da palavra. Em suma, é através dos planos alongados em locação que o espectador de $A$ passarela se foi compartilha com a personagem uma experiência através da qual a geografia do espaço urbano e sua própria geografia emocional parecem estar em desacordo.

Em seu artigo sobre $A$ passarela se foi, Brian Hu sugere que tanto o cinema quanto a cidade são objetos de nostalgia para Tsai: "Como é vividamente demonstrado pelo telão colado em um arranha-céu e gritando palavras de ordem para os pedestres, cidade e cinema estão intimamente relacionados: a corrosão de um é paralela à deterioração do outro" (HU, 2003). Assim, seria possível traçar uma analogia entre a perda da carteira de identidade - e a perda de identidade - da personagem e a efemeridade da cidade que, assolada por constantes mudanças, parece também perder sua identidade. Mas Tsai vai ainda mais longe em sua 
ano 2 número 3

Temáticas

livres

reflexão acerca da permanência e do desaparecimento: Shiang-chyi continua a rondar pela região da Estação Central de Taipei, e aos poucos nos damos conta de que, mais do que a passarela, ela buscava de fato Hsiao Kang, o vendedor ambulante de relógios que conhecera em Que horas são aí?. Em um momento eles se cruzam em uma escada rolante, mas ela não o vê. No penúltimo planosequência Hsiao Kang aparece em um teste de elenco para um filme pornô, vestido como um médico e em frente a uma câmera mini-DV. Ao colocar o avental branco é Hsiao Kang que agora perde a sua identidade, e o $35 \mathrm{~mm}$ dos filmes de Tsai é "substituído" pela câmera digital. Aqui, A passarela se foi ecoa o epílogo de Um gosto de cereja (Ta'm e guilass, 1997) de Abbas Kiarostami, em que, como observa Laura Mulvey (2006, p. 124), a morte do protagonista sugere a morte do cinema, e seu renascimento é operado por meio da imagem do vídeo. Ao posicionar seu ator fetiche e alterego Hsiao Kang em frente a uma câmera digital e como aspirante a ator pornô, Tsai termina por tecer uma bela analogia entre o cinema e a cidade, ou o espaço instável e a imagem instável, à beira do desaparecimento, ou talvez de um recomeço.

O filme seguinte a A passarela se foi, realizado em 2003, recebeu o título em português e em inglês de Adeus, Dragon Inn (Goodbye, Dragon Inn). Em mandarim foi chamado de Bu san, que por si só significa "não deixar", "não deixou" ou "nunca separados", mas que é comumente usado em conjunto com bu jian para formar a expressão "bu jian bu san", que significa "não vamos embora até que nos encontremos". A outra metade dessa frase, Bu jian, foi dirigida por Hsiao Kang no mesmo ano, com o título em inglês The missing. Os dois filmes foram concebidos como um projeto comum e compartilham o tema do desaparecimento. Em Bu san, um antigo cinema localizado em Yong He, um distrito de Taipei, está condenado. O espectador do filme de Tsai compartilha com os espectadores do cinema Fu Ho, e em particular com um jovem rapaz japonês que se abriga da chuva no interior da sala, sua última sessão, com o clássico de wuxia Dragon Gate Inn (Long Men Ke Zhan), dirigido por King Hu em 1966. Não por acaso, a primeira frase dita por um personagem no filme de 1966 (e que pode ser ouvida em Adeus, Dragon Inn) contém a expressão bu san para se referir ao espírito do general Yu, decapitado pelo eunuco rival 
Zhao durante disputas políticas travadas na China do século XV. Zhao sente a presença do espírito de Yu, que não desapareceu (bu san), e decide matar seus filhos, em fuga desde o assassinato de seu pai. Em Adeus, Dragon Inn Tsai brinca com a cronologia do filme de Hu, então a frase bu san só aparece aos 16 minutos de projeção, seguida da suspeita do jovem japonês de que o antigo teatro é assombrado por fantasmas do passado.

Se em $A$ passarela se foi há uma analogia entre o espaço urbano efêmero e as mudanças nos modos de produção do cinema, em Adeus, Dragon Inn o desaparecimento arquitetônico da sala diz respeito às mudanças nos modos de exibição e consumo do cinema. O Fu Ho era um dos muitos cinemas em Taipei, assim como em cidades no mundo todo, que durante décadas fez parte do tecido urbano antes de serem forçados a encerrar as atividades, especialmente nos últimos vinte anos, incapazes de enfrentar a concorrência dos multiplexes e dos "home theatres". Como explica Chan, "o cinema Fu Ho representa a época prévídeo, pré-multiplex, na qual os cinemas ocupavam em geral um edifício único, com uma enorme tela para filmes Cinemascope, e com uma plateia com muitos assentos" (CHAN, 2007, p. 3). O mesmo prédio havia servido como locação em Que horas são aí?, em outra instância do que antes chamei de uma arqueologia da imagem em movimento operando através dos vários filmes de Tsai, que registram e preservam o espaço em desaparecimento. Neste caso particular, foi de fato um impulso urgente para documentar um lugar específico que deu origem ao filme, pois o diretor descobriu por acaso que o cinema estava fechando suas portas, e de um ímpeto ligou para o seu produtor com a ideia de alugar o prédio por seis meses e lá realizar um filme.

A escolha de Dragon Gate Inn para a última sessão não foi aleatória. Primeiramente, o filme de $\mathrm{Hu}$, realizado no período em que o diretor chinês trabalhou em Taiwan, pertence a um tempo em que cinemas gigantescos tais como o Fu Ho ainda atraiam grande público. Em Adeus, Dragon Inn, Tsai reúne os dois filmes - o seu e o de Hu, separados por um lapso temporal de 37 anos - em um mesmo espaço, e a partir daí estabelece um diálogo constante entre os dois. Isso pode ser observado, por exemplo, em duas sequências seminais articuladas pelo campo/contracampo. A primeira mostra Shiang- 
ano 2 número 3

Temáticas

livres

Chyi, que interpreta a bilheteira do cinema, abrindo uma porta abaixo da tela de projeção e olhando para cima. Na próxima cena ela vai para detrás da tela, e seu rosto é visto em primeiro plano, banhado por pontos de luz. Ao encarar Chu Huei, uma mulher disfarçada de homem que vem a Dragon Inn para lutar contra os aliados do eunuco, o vínculo entre as duas personagens femininas é evidenciado através da montagem, que alterna seus rostos em close-up. Nesta sequência, Chu está enfrentando o inimigo do lado de fora da estalagem, e três planos de seu rosto estático, filmados de diferentes ângulos, antecipam a sua decisão de atacar. Shiang-Chyi também enfrenta uma tarefa difícil, evidente nos vários lances de escada que ela tem que subir a despeito de sua dificuldade motora (ela tem uma deficiência física), tudo para chegar ao projecionista, Hsiao Kang, por quem está apaixonada.

Outro exemplo que concatena através da montagem personagens de 2003 e de 1966 ocorre no final do filme. Aqui, os dois atores Chun Shih e Miao Tien, este um dos principais atores da obra de Tsai Ming-liang sempre no papel do pai de Hsiao Kang, emocionam-se com suas próprias imagens em Dragon Gate Inn, vindas do passado e reanimadas pelo movimento do projetor e pela luz que o atravessa. Eles trocam um olhar, sentados como estão em fileiras separadas, e os cortes alternam entre o espaço da plateia e o duelo na tela. A sequência termina com um plano primeiro de Chun Shih, cujos olhos se enchem de lágrimas. Em sua admiração de seu próprio passado, a capacidade do cinema de preservar as coisas (uma passarela, o sala Fu Ho) vem novamente à tona, desta vez através da projeção de um filme 1966, que preservou e imortalizou as versões jovens dos atores. Tsai comenta essa tensão entre a quietude e o movimento, entre a vida e a morte, ao sugerir que "o filme pode transformar algo em eterno. Ele preserva a juventude, mas também significa morrer. Tudo o que você filma está também morrendo lentamente. Tudo o que você filma não está mais lá" (REICHERT e SYNGLE, 2004). O cinema, como sugeriu Laura Mulvey, nada mais é do que a morte 24 vezes por segundo (MULVEY, 2006, p. 15).

Não por acaso, é possível traçar outros paralelos entre o filme de $\mathrm{Hu}$ e o de Tsai. Ambos, por exemplo, se desenrolam em um espaço público. No filme de $\mathrm{Hu}$ esse local é a estalagem, um tropo comum no gênero wuxia, no qual 
toda a ação tende a estar concentrada em um só lugar. É dentro dos limites da estalagem que heróis e vilões se encontram, e onde todo tipo de intriga e trama acontece a portas fechadas, por meio de corredores e passagens. O mesmo tipo de encontros casuais acontece no cinema Fu Ho, também pleno de espaços fechados, bastidores escuros, longos e sinistros corredores, cortinas e portas. A sala de cinema é, contudo, um prédio urbano, e os encontros que promove também podem ser relacionados à atividade dos pedestres na cidade, assim como ao seu aspecto contingente.

Esse tipo de sala antiga, que prosperou até a década de 1970, geralmente ocupava um único edifício, assim como um templo, convidando a uma experiência ritualística e ao mesmo tempo pública e privada. Diferente da televisão, que pertence ao cotidiano, ao espaço "não santificado" da sala doméstica, a sala de cinema tinha uma aura, tendo sido definida por Michel Foucault em Des Espaces autres (1984) como uma das instâncias de heterotopia, um espaço que contém todos os outros espaços. Nessa heterotopia filmada por Tsai, a contradição, inerente ao cinema, entre presença e ausência, entre o espaço virtual e os corpos condenados à circulação, é exagerada por indícios de que a sala Fu Ho é assombrada. A luz verde que permeia o longo corredor do cinema, e que banha uma mulher a comer sementes de abóbora (Yang Kuei-Mei), é um desses indícios, o verde tendo sido utilizado como uma convenção no cinema para designar as ligações com o mundo do além, eternizado por Alfred Hitchcock em Um corpo que cai (Vertigo, 1958) ${ }^{4}$. A dupla presença das versões jovens e velhas de Miao Tien e Chun Shih é outra indicação da existência de fantasmas no Fu Ho, provocando no rapaz japonês o sentimento do "estranho" freudiano: seriam eles reais ou irreais, estariam vivos ou mortos? Finalmente, ao sair da sala de projeção e explorar os corredores do cinema, o moço japonês encontra alguém que lhe pergunta "Você sabia que esse cinema tem fantasmas?".

Tanto a dimensão assombrada do cinema quanto os elementos autobiográficos presentes em Adeus, Dragon Inn reaparecem no sonho do diretor Tsai, que

4. Em Um corpo que cai, a luz de néon verde do lado de fora do apartamento de Judy a cobre assim que ela sai do banheiro vestida como Madeleine. 
ano 2 número 3

Temáticas

livres

ganha vida em seu filme de 23 minutos It's a dream (Shi meng), de 2007. Este filme, que tem uma versão mais curta de três minutos e 19 segundos no filme de episódios Cada um com seu cinema (Chacun son cinéma, 2007), realizado em outro cinema abandonado, desta vez na Malásia, terra natal do diretor. Este filme também sinaliza uma nova dimensão nas mudanças que afetam os modos de exibição do cinema, pois encontrou seu espaço não nas salas de cinema, mas sim no museu, tendo sido inicialmente criado como uma instalação em 2007 para a Bienal de Veneza, mais tarde transferido para o Museu de Artes Plásticas de Taipei como parte da exposição “Memória de uma viagem” (2010). Significativamente, Visage, último filme de Tsai de 2009, foi uma encomenda do Museu do Louvre na França, e também se tornou parte de sua coleção permanente. Em entrevista ao Taipei Times o diretor comentou sobre o fato de o cinema estar gradualmente encontrando novos lares, declarando que "isso soa como uma contradição, mas os filmes precisam deixar as salas de cinema a fim de ressuscitarem" (BUCHAN, 2010).

Se Adeus, Dragon Inn pode ser visto como o canto do cisne das antigas salas de cinema, It's a dream rememora a infância do diretor dentro de outra grande sala, com assentos igualmente vermelhos, e igualmente obsoletos. Antes de entrar na instalação, onde o filme rodado em $35 \mathrm{~mm}$ é projetado em formato DVD, o visitante do museu lê a seguinte declaração do diretor:

É um sonho

Tsai Ming-liang

Você veio assistir a meu filme

Você entrou e se sentou nos assentos vermelhos de nylon

Velhos, batidos e cheios de manchas

Eles vieram de um longínquo cinema fechado

Arrancados, eles foram transportados até aqui

Em uma cidade apagada, o cinema continua a desaparecer

É aqui que faço meu filme de 23 minutos

Um sonho meu, na verdade

Sonhei que eu tinha cinco anos

Hsiao Kang interpretou o meu pai

Minha mãe, ainda viva na época, fez o papel dela mesma. 
Ninguém na plateia, todos os lugares vazios

Lá eu coloquei uma foto de uma avó morta, de uma família que eu não conheço

Jogando pedras e queimando incenso, pedi que ela voltasse

Para interpretar a minha avó

Toda vez que ela me levava ao cinema, ela sempre me comprava algumas peras

Na verdade, o cinema com que sonhei há muito foi demolido

Em um lugar diferente, eu vi um cinema diferente

Ele parecia estar me chamando:

Filme-me! Apresse-se e venha me filmar! ${ }^{5}$

A última frase exprime, através de seu modo imperativo, um sentimento de urgência diante do desaparecimento do cinema, que estaria ele próprio chamando o diretor. ${ }^{6}$ Dentro da sala, o público se acomoda em assentos desgastados vindos do cinema abandonado na Malásia, posicionados de forma

\author{
5. 是夢 \\ 你決定看我的電影了。 \\ 你走進來坐在紅色尼線塑料沙發席上。 \\ 它們已經陳舊破損满是污跡 \\ 從遠方一家歇点已久的老戲院拆運過來的。 \\ 那家老戲院在一個沒落的鄉鎮繼續腐爛著。 \\ 我在那裡拍了這部二十三分鐘的電影。 \\ 其實是我的营。 \\ 夢到我五歲的模樣。 \\ 小康演我的父親。 \\ 當時還在世的母親演她自己。 \\ 無人的觀眾席上安置著一張不知誰家老太太的遺照。 \\ 上香擲杯情她也來參加演出。 \\ 演我的外婆。 \\ 她每次带我去戲院總會給我買一串梨。 \\ 其實我夢中的戲院早就被拆掉了。 \\ 我在另一個地方遇見另一家。 \\ 它好像在對我召喚, 拍我吧! 趕快拍我吧!
}

6. O diretor Tsai me contou em entrevista em Taipei (2010) que realizou seu último filme, Madame Butterfly (Hu Die Fu Ren, 2009), na estação central de ônibus de Kuala Lumpur, demolida um ano depois. Ele brincou que as pessoas estão com medo de serem filmadas por ele, já que correm também o risco de desaparecer. Curiosamente, o curta-metragem que filmou em São Paulo para a Mostra Internacional de Cinema (Aquário, 2004) consistiu em uma observação do Edifício São Vito, no centro da cidade, demolido em 2010/11. 
ano 2 número 3

Temáticas

livres

não linear. Eles são os mesmos assentos vistos no filme, criando uma forte ligação espacial entre a sala de exposições e o que está sendo projetado na tela. Mais uma vez, o filme preservou aquilo que passou, e convida o público a embarcar em um sonho, na memória de uma viagem pela infância do diretor e através de uma sala de cinema.

A ideia para essa viagem veio com a descoberta dentro da sala de cinema na Malásia da foto de uma senhora idosa, colocada sobre um dos assentos. Seu filho explicou mais tarde a Tsai que sua mãe adorava ir ao cinema, e que por isso ele ainda a levava lá após sua morte (BURDEAU, 2007, p. 47). A foto foi assim incorporada ao filme, e tornou-se a avó do diretor, que através da queima de incenso e do jogar das pedras - uma tradição nos templos taoistas - é trazida de volta à vida por Pearlly Chua. A atriz malaia entra na sala, toma um lugar e começa a comer peras arranjadas em um espeto, oferecendo-as ao homem que fuma na fileira de trás. Antes dessa aparição fantasmagórica, Hsiao Kang, no papel de pai do diretor, havia acendido o queimador de incenso e compartilhado com a mãe do diretor (interpretada por sua mãe real) e com um menino, interpretado pelo sobrinho de Hsiao Kang, pedaços de durians, uma fruta nativa do sudeste asiático de cheiro e gosto característico. Na trilha sonora, a voz off de Tsai começa a relatar esse sonho: "Eu sonhei com meu pai ainda jovem...".

A cena final do filme, que dura cerca de dez minutos, tem Hsiao Kang sentado ao lado do menino, da mãe e da fotografia da avó. Muito lentamente, começamos a perceber que seus corpos estão desaparecendo de dentro do cinema. Juntas, suas imagens se tornam cada vez mais granuladas, até que desaparecem por completo, deixando os lugares vazios. Uma delas, porém, permanece: a fotografia da velha avó. Como afirmou André Bazin em seu ensaio seminal "A Ontologia da imagem fotográfica", 
mecânico impassível; pois a fotografia não cria a eternidade como a arte, ela embalsama o tempo, resgatando-o simplesmente de sua própria corrupção. (BAZIN, 2002, p. 14)

Assim, em It's a dream, desaparecem o pai, a mãe e o menino, mas fica a fotografia da avó desconhecida, “livre de seu destino". Esse passado persistente, embalsamado na imagem fotográfica, sobrevive ao desaparecimento dos outros corpos, assim como o cinema é capaz de preservar os vestígios do tecido urbano a despeito de sua efemeridade.

\section{Nostalgia, Cinefilia, Flânerie}

Pode-se dizer que o modo através do qual a relação entre o cinema e a cidade é articulado por Tsai não esconde certa ansiedade diante do desaparecimento, ou até mesmo um sentimento profundo de nostalgia. Isso parece evidente no uso de versões completas de antigas canções chinesas das décadas de 1940, 1960 e 1970 nos três filmes aqui analisados. A passarela se foi, por exemplo, termina com "Nan Ping Wan Zhong”, cantada por Chui Ping na década de 1970. A canção acompanha imagens do céu azul, como uma lembrança daquela passarela ${ }^{7}$ que não está mais lá. Já a letra conta a história de alguém perdido em uma floresta e que ao escutar o sino da noite sente saudades de um ente querido. Já em Adeus, Dragon Inn a canção “Liu Lian” (na versão dos anos 1960 de Li Yao), um lamento sobre a persistência das memórias e do passado, acompanha os créditos finais. Por fim, a canção "Shi Meng Shi Zhen”, cantada por Kung Chiu Hsiao nos anos 1940, é utilizada em It's a dream. Seu título significa "seria um sonho ou realidade?", e não por acaso a primeira metade do mesmo coincide com o título do filme (Shi meng).

O uso de canções antigas complementa o subtexto nostálgico desses filmes sobre a transformação e o desaparecimento, no momento em que os modos de produção e exibição do cinema estão mudando inexoravelmente com o 
ano 2 número 3

Temáticas

livres

advento da tecnologia digital e as já muito discutidas "perda da indexicalidade" e "morte da cinefilia" (WILLEMEN, 1994; DOANE, 2002). Se por um lado é plausível argumentar que o traço indéxico da imagem fotográfica ainda persiste na imagem digital, por outro lado parece inevitável que a forma de cinefilia associada ao filme em película tenda realmente a desaparecer ou a se transformar. Pois a cinefilia é essencialmente um fenômeno urbano, e o cinéfilo era aquele que habitava as salas de cinema, movimentando-se entre elas em uma espécie de flanêrie. Se esses edifícios desaparecem, os cinéfilos urbanos também tendem a desaparecer, e o amor ao cinema, por sua vez, tende a transformar-se cada vez mais - do VHS ao DVD e à Internet - em um assunto doméstico. Diante desse quadro de transformações, $A$ passarela se foi, Adeus, Dragon Inn e It's a dream me parecem especialmente reveladores ao lançarem um olhar sobre o desaparecimento arquitetônico das salas de cinema, sobre a transferência do filme para uma nova casa no museu e sobre as mudanças no tecido urbano e na forma de consumir e amar o cinema. Um olhar carregado de melancolia e beleza, unindo cinema e cidade, presença e ausência, permanência e desaparecimento, representação e materialidade, assim como a vida e a morte, mas também a ressurreição. 


\section{Referências}

ANDREW, Dudley. "Ghost towns", in Braester, Yomi e Tweedie, James (orgs), Cinema at the city's edge: film and urban networks in east Asia. Hong Kong: Hong Kong University Press, 2010.

BAUDELAIRE, Charles. Les fleurs du mal. Paris: Garnier-Flammarion, 1964.

BAZIN, André. Qu'est-ce que le cinéma? Paris: Les Éditions du Cerf, 2002.

BRUNO, Giuliana. Atlas of emotion: journeys in art, architecture and film. New York: Verso, 2007.

. "City views: the voyage of film images", in The cinematic city, edited by Clarke, David B. London: Routledge,1997, pp. 46-58.

BUCHAN, Noah (2010), “Interview: film's death and resurrection”, Taipei Times, 2010. Disponível em http://www.taipeitimes.com/News/feat/archives/2010/03/25/2003468911/4. Acesso em: 10 jan. 2013

BURDEAU, Emmanuel E THIRION, Antoine. "L'esprit révolutionnaire”, Cahiers du Cinéma, 624, 2007, pp. 45-7.

CHAN, K. (2007), “Goodbye, dragon Inn: Tsai Ming-liang's political aesthetics of nostalgia, place, and lingering", Journal of Chinese Cinemas, 1: 2, 2007, pp. 89-103.

DELEUZE, Gilles. Cinéma 1: L’Image-mouvement. Paris: Les Editions de Minuit, 1985. . Cinéma 2: L'Image-temps. Paris: Les Editions de Minuit, 1985.

DOANE, Mary Ann. The emergence of cinematic time: modernity, contingency, the archive. Cambridge, MA/London: Harvard University Press, 2002.

EISENSTEIN, Sergei. Towards a theory of montage: v. 2, edited by Michael Glenny and Richard Taylor. London: I.B. Tauris, 2010.

FOUCAULT, Michel. "Des espaces autres". Architecture, mouvement, continuité 5, Octobre 1984([1967] 1984), pp. 46-9.

FREUD, Sigmund. "O estranho", in Obras completas Vol. XVII. Rio de Janeiro: Imago, 1976. 
HALLAM, Julia. "Film, space and place: researching a city in film", in New Review of Film and Television Studies, v. 8, n 3, 2010, pp. 277-296.

HU, Brian. "Goodbye city, goodbye cinema: nostalgia in Tsai Ming-liang's The Skywalk is Gone". Senses of Cinema. 2003. Disponível em: http://www.sensesofcinema.com/2003/ feature-articles/skywalk_is_gone/. Acesso em 10 jan. 2013.

LURY, Karen e MASSEY, Doreen. “Making connections”, Screen, 40:3, 1999, pp. 229-238.

MASSEY, Doreen. Pelo espaço. Rio de Janeiro: Bertrand Brasil, 2008.

MULVEY, Laura. Death $24 x$ a second: stillness and the moving image. London: Reaktion Books, 2006.

REHM, Jean-Pierre, JOYARD, Olivier and RIVIÈRE, Danièle. Tsai Ming-liang. Paris: Dis Voir 1999.

REICHERT, Jeff e SYNGLE, Erik. “Ghost writer: reverse shot talks to Tsai Ming liang”, Reverse shot. 2004. Disponível em: www.reverseshot.com/legacy/winter04/tsai.html. Acesso em 10 jan. 2013.

REYNAUD, Bérénice. “Entretien avec Tsai Ming-liang”, Cahiers du Cinéma 516, 1997, pp. 35-7.

WILLEMEN, Paul. Looks and frictions: essays in cultural studies and film theory. London: British Film Institute, 1994.

WOOD, C. "Realism, intertextuality and humour in Tsai Ming-liang's Goodbye, Dragon Inn", Journal of Chinese Cinemas 1: 2, 2007, pp. 105-116. 